\title{
Crisis management during anaesthesia: pulmonary oedema
}

\author{
M J Chapman, J A Myburgh, M T Kluger, W B Runciman
}

Qual Saf Health Care 2005;14:e8 (hHtp://www.qshc.com/cgi/content/full/14/3/e8). doi: 10.1136/qshc.2002.004267

See end of article for authors' affiliations

.....................

Correspondence to:

Professor W B Runciman,

President, Australian

Patient Safety Foundation,

GPO Box 400, Adelaide,

South Australia 5001

Australia; research@apsf.

net.au

Accepted 11 January 2005
Background: Pulmonary oedema may complicate the perioperative period and the aetiology may be different from non-operative patients. Diagnosis may be difficult during anaesthesia and consequently management may be delayed.

Objectives: To examine the role of a previously described core algorithm "COVER ABCD-A SWIFT $\mathrm{CHECK}^{\prime \prime}$, supplemented by a specific sub-algorithm for pulmonary oedema, in its management occurring in association with anaesthesia.

Methods: The potential performance of this structured approach for each of the relevant incidents among the first 4000 reported to the Australian Incident Monitoring Study (AIMS) was compared with the actual management as reported by the anaesthetists involved.

Results: Pulmonary oedema was identified in $35(<1 \%)$ of the first 4000 reports to AIMS. The most frequent presenting sign was hypoxia $(46 \%)$ and the most specific sign was the presence of frothy sputum (23\%). The core algorithm, although successful in the management of the initial physiological upset, was found to be inadequate for the ongoing management of pulmonary oedema. A specific sub-algorithm for the management of perioperative pulmonary oedema was devised, tested against the reports and would have been effective, if properly applied, in the management of all but one of the reported cases.

Conclusion: Successful recognition and management of perioperative pulmonary oedema is likely with the application of the structured algorithm and specific sub-algorithm approach outlined in this study.
$\mathrm{P}$ ulmonary oedema is the abnormal accumulation of fluid in the interstitial or alveolar spaces of the lung. It occurs for a number of reasons which can be explained on the basis of a disturbance in the normal Starling equation. ${ }^{1}$ It involves changes in hydrostatic or oncotic pressure across the alveolar membrane or in the permeability of the alveolar membrane such that fluid moves across from the capillaries into the alveolar space. Traditional teaching is that pulmonary oedema occurring in patients outside hospital tends to be cardiac in aetiology, with usually left heart diastolic dysfunction causing back pressure across the pulmonary system, resulting in extravasation of fluid into the alveoli. However, recent evidence suggests that increased afterload as in neurogenic pulmonary oedema may also be important in cardiogenic causes.

In patients undergoing anaesthesia, causes of pulmonary oedema other than cardiogenic are encountered. Decreased plasma oncotic pressure (due to hypoproteinaemia), fluid overload, alterations in the permeability of the alveolarcapillary membrane (such as typically seen in acute respiratory distress syndrome (ARDS)), and post-obstructive and neurogenic pulmonary oedema ${ }^{1-5}$ may all occur. In many cases the aetiology is multifactorial with no clear identifiable precipitant. Because recognition may be delayed and management variable, it was decided to examine the place of a structured approach to the diagnosis and management of pulmonary oedema occurring in association with general anaesthesia.

In 1993 a "core" crisis management algorithm, represented by the mnemonic COVER ABCD-A SWIFT CHECK (the AB precedes COVER for the non-intubated patient) was proposed as the basis for a systematic approach to any crisis during anaesthesia where it is not immediately obvious what should be done or where actions taken have failed to remedy the situation. ${ }^{6}$ This was validated against the first 2000 incidents reported to the original Australian Incident Monitoring Study (AIMS). AIMS is an ongoing study which involves the voluntary anonymous reporting of any unintended incident which reduced or could have reduced the safety margin for a patient.

It was concluded that, if this algorithm had been correctly applied, a functional diagnosis would have been reached within 40-60 seconds in 99\% of applicable incidents, and that the learned sequence of actions recommended by the COVER portion would have led to appropriate steps being taken to handle the $60 \%$ of problems relevant to this portion of the algorithm. ${ }^{6}$ However, this study also showed that the $40 \%$ of problems represented by the remainder of the algorithm ABCD-A SWIFT CHECK were not always promptly diagnosed or appropriately managed..$^{6-8}$ It was decided that it would be useful, for these problems, to develop a set of subalgorithms in an easy-to-use crisis management manual. ${ }^{9}$ This study reports on the potential place of the COVER ABCD-A SWIFT CHECK algorithm in the diagnosis and initial management of pulmonary oedema, provides an outline of a specific crisis management sub-algorithm for this problem, and provides an indication of the potential value of using this structured approach.

\section{METHODS}

Of the first 4000 incidents reported to AIMS, those that made reference to pulmonary oedema were extracted and analysed for relevance, presenting features, type of surgery, cause, management and outcome. The COVER ABCD-A SWIFT CHECK algorithm, as presented elsewhere in this series of papers, ${ }^{9}$ was applied to each relevant report to determine the stages at which the problem might have been diagnosed and to confirm that activating the COVER portion would have led to appropriate initial steps being taken. As pulmonary oedema is not dealt with by this algorithm, a specific subalgorithm was developed (see fig 1) and its putative effectiveness was tested against the reports. How this was done is described elsewhere in this series of articles. ${ }^{9}$ The potential value of this structured approach-that is, the application of COVER ABCD-A SWIFT CHECK to the diagnosis and initial management of this problem and the 


\section{PULMONARY OEDEMA/ARDS}

\section{SIGNS (1)*}

Respiratory distress/tachypnoea

Desaturation

Increased inspiratory pressure

Pink frothing sputum up ETT ILMA (diagnostic)

Crepitations or bronchospasm

\section{PRECIPITATING FACTORS}

Fluid overload (2)

Non cardiogenic:

Post airway obstruction (3)

Anaphylaxis

Neurogenic

Sepsis

Pulmonary aspiration

Multiple organ failure

Cardiogenic (4)

\section{EMERGENCY MANAGEMENT}

Titrate inspired oxygen concentration against $\mathrm{SpO}_{2}$ Head up tilt/sit up

If self ventilating/apply CPAP (5)

Intubate if necessary

IPPV and PEEP if intubated

Consider drug therapy: morphine/GTN/frusemide (6)

The sub-algorithm forms a facing page of the Crisis Management Manual 12.

* Numbers in brackets refer to Notes in the right hand panel.

Figure 1 Pulmonary oedema/ARDS.

application of the sub-algorithm for pulmonary oedemawas assessed in the light of the AIMS reports by comparing its potential effectiveness for each incident with that of the actual management as recorded in each report.

\section{RESULTS}

Pulmonary oedema was mentioned in 37 reports $(<1 \%)$ but, in two of these, pulmonary oedema was not one of the active problems at the time of the incident. This left 35 reports which constitute the database for this study.

The aetiology of the pulmonary oedema was varied. It was associated with fluid overload in 16 patients $(46 \%)$, most of whom $(81 \%)$ had a clinical condition that may have made them more susceptible to fluid overload. These conditions included age $>70$ years, a past history of cardiac disease or hypertension, renal failure, and chronic obstructive airways disease. It occurred following upper airway obstruction in

\section{FURTHER CARE}

Consider and investigate likely cause

Review perioperative fluid balance/renal function

Non-cardiogenic: consider post airway obstruction

Allergy/anaphylaxis $\rightarrow$ page $48^{*}$

Aspiration $\rightarrow$ page $16^{*}$

Sepsis $\rightarrow$ page $64^{*}$

Multiple organ failure, eg major trauma, pancreatitis

Renal - renal function tests

Cardiogenic:

ECG

Cardiac enzymes

Echocardiogram

Chest X-ray

Consider admission to high dependency area/ICU

The COVER ABCD-A SWIFT CHECK algorithm was successful in the management of the initial physiological upset, however it was considered that the use of this specific sub-algorithm would be required once the initial diagnosis of pulmonary oedema was made.

(1) Hypoxia $-46 \%$; pink frothy sputum - 23\%; increased airway pressures $-14 \%$; respiratory distress $-14 \%$; crepitations or wheeze $-9 \%$.

(2) Fluid overload was judged to be the cause in $46 \%$ of incidents. $81 \%$ of these had pre-existing conditions making them more susceptible to overhydration: age $>70$, cardiovascular disease or hypertension, renal failure and chronic airflow limitation.

(3) $23 \%$ of incidents were judged to be post upper airway obstruction.

(4) $14 \%$ were judged to be cardiogenic in origin, eg. valvular heart disease, ischaemia/infarction, cardiac failure, arrhythmia.

(5) CPAP is important specific therapy for pulmonary oedema (in addition to treatment for hypoxia).

(6) Preload reduction: Morphine $1 \mathrm{mg}$ IV doses

GTN infusion $50 \mathrm{mg}$ in $500 \mathrm{ml}$

Commence at $0.1 \mathrm{ml} / \mathrm{kg} / \mathrm{hr}$

Fluid reduction:

Frusemide $0.5 \mathrm{mg} / \mathrm{kg} \mathrm{IV}$ if fluid overload (place urinary catheter) If hypotensive:

Adrenaline infusion: start with $0.00015 \mathrm{mg} / \mathrm{kg} / \mathrm{min}$

Adrenaline: for easy adult dosing, see page $71^{*}$

Titrate against heart rate and blood pressure

These notes comprise a reverse side of a page of the

Crisis Management Manual 12 .

* Page numbers refer to the Crisis Management Manual 12 . eight patients (23\%), appeared to be cardiogenic in five $(14 \%)$, and to be due to neurogenic causes and anaphylaxis in one case each. Three $(9 \%)$ had no obvious cause for the pulmonary oedema from examination of the report.

Seventeen $(49 \%)$ of the incidents occurred outside the operating or procedure room. The COVER algorithm is not relevant to these incidents as it is designed for patients breathing gas from an anaesthetic machine. Twenty three of the patients $(66 \%)$ were admitted to the intensive care unit and two $(6 \%)$ died. Neither death could be directly attributed to the pulmonary oedema.

There were a number of symptoms or signs alerting the anaesthetist to the presence of pulmonary oedema as listed in fig 1. Hypoxia presenting as desaturation or cyanosis was the commonest sign $(46 \%)$. Pink frothy sputum was noted in $23 \%$ and is diagnostic of pulmonary oedema. Increased airway pressure was observed in $14 \%$, respiratory distress in 
$14 \%$, and pulmonary crepitations or wheeze on auscultation of the chest in $9 \%$.

In none of these cases was the COVER algorithm adequate alone to deal with the incident as the initial problem progressed to a diagnosis of pulmonary oedema. When the sub-algorithm for pulmonary oedema (fig 1) was tested against these incidents, once the diagnosis was made, it was thought that it would have been successful in all but one of the cases. This was one death which appears to have been unavoidable due to uncontrollable bleeding in a patient with pre-existing cardiac failure.

\section{DISCUSSION}

Pulmonary oedema is a potential cause of hypoxia in the perioperative patient. The accumulation of excessive alveolar fluid results in hypoxia due to interference with diffusion across the alveolar capillary membrane. Frothy (sometimes bloodstained) sputum may be expectorated or observed in the endotracheal tube. This is a pathognomonic sign of pulmonary oedema which, as indicated above, may have various aetiologies. The diagnosis of pulmonary oedema may be supported by finding crepitations and sometimes wheezes on auscultation of the lung. However, these may also be heard with aspiration pneumonitis or infection. A chest radiograph may help to confirm the diagnosis but is not specific. Generalised opacity is characteristic with a typical perihilar "bat's wing" appearance. However, the opacity may be unilateral or asymmetrical, particularly in the acute period $(<4$ hours). Alveolar opacities on the chest radiograph may also be due to inhalation of enteric contents, infection, or alveolar haemorrhage. The diagnosis of pulmonary oedema is made on assessment of the combination of history, symptoms, clinical signs, and investigations and on excluding alternative diagnoses such as aspiration pneumonitis and pneumonia.

Increased permeability (or non-cardiogenic) pulmonary oedema (ARDS) may be differentiated from normal permeability pulmonary oedema by assessing cardiac filling pressures. This can be done by examination of the jugular venous pressure or invasively with a central venous or pulmonary artery catheter. A pulmonary artery occlusion pressure of $18 \mathrm{~mm} \mathrm{Hg}$ is regarded by convention as a threshold pressure differentiating the two. However, this is not specific as normal filling pressures may be seen in cardiogenic pulmonary oedema, particularly in patients on mechanical ventilation. Similarly, cardiac compromise may coexist in a patient with ARDS.

When pulmonary oedema is suspected a cause should always be sought. The causes listed in fig 1 are those commonly found in perioperative patients. Post-obstructive pulmonary oedema is a rare entity outside the operating suite and intensive care unit. It may be over reported here due to its association with the reportable incident of airway obstruction and its dramatic appearance in patients who are often previously fit and well. ${ }^{2}{ }^{3}$ The pathophysiological basis for this entity is not well understood..$^{11}$

Pulmonary oedema will usually present with hypoxia. If it occurs during anaesthesia, the presenting signs will be apparent using COVER in $95 \%$ of cases, with a further $5 \%$ during consideration of the A in ABCD. Definitive diagnosis relies on recognising a pattern of signs and symptoms, but may not be possible in some cases until intravascular pressures have been measured and other investigations have been undertaken. Once the diagnosis of pulmonary oedema is made, this sub-algorithm should then be followed. However, the physiological abnormalities sometimes have been reversed by COVER before this sub-algorithm is reached.

Finally, it is important that a full explanation of what happened be given to the patient, that the event and the

\section{Key messages}

- Pulmonary oedema was identified in $35(<1 \%)$ of the first 4000 AIMS reports.

- In 16 cases (46\%) pulmonary oedema was associated with fluid overload; most of these patients had a clinical predisposition to this complication.

- Seventeen of the cases $(49 \%)$ occurred outside the operating room.

- Twenty three patients $(66 \%)$ were admitted to the ICU, two of whom died.

- One of the deaths with uncontrollable bleeding in the presence of pre-existing cardiac failure was considered unavoidable.

- The diagnostic sign of pulmonary oedema, pink frothy sputum, was reported in $23 \%$ of the cases.

- Pulmonary oedema will usually present with hypoxia. Definitive diagnosis relies upon recognising a pattern of signs and symptoms.

- The differentiation between normal and increased permeability forms of pulmonary oedema requires the assessment of cardiac filling pressures.

- While the COVER ABCD core algorithm will serve to detect all presenting signs in pulmonary oedema, in none of the cases was it adequate alone to deal with the incident.

- Once the diagnosis was made, the specific subalgorithm was considered to be successful in the management of all but the one case referred to above.

results of any tests should be documented in the anaesthetic record, and that the patient be given a letter to warn future anaesthetists. If a particular precipitating event was significant or a particular action was useful in resolving the crisis, this should be clearly explained and documented.

\section{CONCLUSION}

Pulmonary oedema occurred in less than $1 \%$ of the 4000 perioperative incidents reported to AIMS. Initial management as suggested by the COVER ABCD algorithm and the pulmonary oedema sub-algorithm will sometimes be successful in treating the physiological abnormalities before a diagnosis is made. A sub-algorithm aimed at the management of perioperative pulmonary oedema was developed. This has been tested against the 35 incidents reported and appears to be appropriate.

\section{ACKNOWLEDGEMENTS}

The authors would like to thank all the anaesthetists in Australia and New Zealand who contributed to the 4000 incident reports upon which this and the other 24 papers in the Crisis Management Series are based. The coordinators of the project also thank Liz Brown for preparing the draft of the original Crisis Management Manual; Loretta Smyth for typing; Monika Bullock RN for earlier coding and classifying of data; Dr Charles Bradfield for the electronic version of the algorithms; Dr Klee Benveniste for literature research; and Drs Klee Benveniste, Michal Kluger, John Williamson and Andrew Paix for editing and checking manuscripts.

\section{Authors' affiliations}

M J Chapman, Senior Staff Specialist, Intensive Care Unit, Royal Adelaide Hospital, and University of Adelaide, Adelaide, South Australia, Australia 
J A Myburgh, Associate Professor, University of New South Wales and Director of Research, Department of Intensive Care Medicine, The St George Hospital, Sydney, Australia

M T Kluger, Senior Staff Specialist, Department of Anaesthesiology and Perioperative Medicine, North Shore Hospital, Auckland, New Zealand W B Runciman, Professor and Head, Department of Anaesthesia and Intensive Care, University of Adelaide and Royal Adelaide Hospital, Adelaide, South Australia, Australia

The study was coordinated by the Australian Patient Safety Foundation, GPO Box 400, Adelaide, South Australia 5001, Australia.

\section{REFERENCES}

1 Bersten AD, Soni N, Oh TE. Oh's Intensive Care Manual, 5th ed. Edinburgh: Butterworth-Heinemann, 2003.

2 Koh MS, Hsu AA, Eng P. Negative pressure pulmonary oedema in the medical intensive care unit. Intensive Care Med 2003;29:1601-4.

3 Patton WC, Baker CL. Prevalence of negative-pressure pulmonary edema at an orthopaedic hospital. J South Orthop Assoc 2000;9:248-53.

4 Quader K, Manninen PH, Lai JK. Pulmonary edema in the neuroradiology suite: a diagnostic dilemma. Can J Anaesth 2001;48:308-12.
5 Pandey CK, Mathur N, Singh N, et al. Fulminant pulmonary edema after intramuscular ketamine. Can J Anaesth 2000;47:894-6.

6 Runciman WB, Webb RK, Klepper ID, et al. Crisis management: validation of an algorithm by analysis of 2,000 incident reports. Anaesth Intensive Care 1993;21:579-92.

7 Webb RK, Currie M, Morgan CA, et al. The Australian Incident Monitoring Study: an analysis of 2,000 incident reports. Anaesth Intensive Care 1993:21:520-8.

8 Webb RK, van der Walt JH, Runciman WB, et al. Which monitor? An analysis of 2000 incident reports. Anaesth Intensive Care 1993;21:529-42.

9 Runciman WB, Kluger MT, Morris RW, et al. Crisis management during anaesthesia: the development of an anaesthetic crisis management manual. Qual Saf Health Care 2005; 14:e1.

10 Kollef MH, Pluss J. Noncardiogenic pulmonary edema following upper airway obstruction. Seven cases and a review of the literature. Medicine (Baltimore) 1991:70:91-8.

11 McConkey PP. Postobstructive pulmonary oedema: a case series and review. Anaesth Intensive Care 2000;28:72-6.

12 Australian Patient Safety Foundation. Crisis Management Manual: COVER $A B C D$ A SWIFT CHECK. Adelaide: Australian Patient Safety Foundation, 1996, 74. Available at http://www.apsf.net.au/anaesthesia.htm (accessed 6 September 2004). 